\title{
AVALIAÇÃO DOS RESÍDUOS DE UMA SERRARIA PARA A PRODUÇÃO DE CELULOSE KRAFT
}

\author{
EVALUATION OF WOOD WASTE OF ONE SAWMILL TO KRAFT PULP PRODUCTION
}

\author{
Lucas Cândido Barbosa ${ }^{1}$ Cristiane Pedrazzi ${ }^{2}$ Érika da Silva Ferreira ${ }^{3}$ Guinter Neutzling Schneid ${ }^{4}$ \\ Vania Karine Dick Wille ${ }^{5}$
}

\begin{abstract}
RESUMO
As indústrias de base florestal apresentam baixo rendimento e geram grande quantidade de resíduos, especialmente as indústrias de transformação primária como, por exemplo, as serrarias. No Brasil, estão sendo criadas iniciativas para aliar a utilização desses resíduos à produção de celulose. Dentro deste propósito, o presente trabalho teve como objetivos avaliar o rendimento de uma serraria de médio porte localizada no município de Rio Grande, RS, e promover análises físico-químicas dos resíduos gerados na etapa de desdobro. Foram utilizadas 20 toras de Pinus elliottii, divididas em duas classes diamétricas. Os resíduos, com exceção da serragem, coletados para análises, encontravam-se dispostos no pátio da empresa, na forma de cavacos. As seguintes propriedades físico-químicas dos cavacos foram analisadas: densidade básica, teor de extrativos solúvel em acetona, grupos acetilas, lignina solúvel e insolúvel em ácido (lignina Klason), grupos urônicos e carboidratos. Como principais resultados verificou-se um ligeiro aumento do rendimento em madeira serrada das madeiras de maiores diâmetros em relação às de menores diâmetros. Das análises físico-químicas foram obtidos os seguintes resultados: densidade básica de $0,402 \mathrm{~g} / \mathrm{cm}^{3}$, teor de celulose de $37,42 \%$ e de $24,37 \%$ para hemiceluloses, lignina Klason de $26,75 \%$ e teor de extrativos de $3,80 \%$. Concluiu-se, nesse estudo, que o baixo rendimento da serraria foi devido à falta de uma classificação diamétrica e diagramas de cortes apropriados para as toras, o que resulta em maior perda de madeira na forma de resíduos. Em relação às características química e física dos resíduos madeireiros, os resultados mostraram-se dentro dos padrões de qualidade da madeira utilizada para a produção de celulose $k r a f t$ de fibra longa e, em algumas situações, apresentando vantagens em relação às madeiras mais jovens usualmente utilizadas pela indústria.
\end{abstract}

Palavras-chave: Pinus elliottii; resíduos de serraria; celulose kraft.

\section{ABSTRACT}

The forest-based industries have low yield and generate large amounts of waste, especially the primary processing industries, such as sawmills. In Brazil, initiatives are being created to combine the use of sawmill residues to pulp production. With this in mind, this study aimed to evaluate the performance of a

1 Engenheiro Industrial Madeireiro, Mestrando pelo Programa de Pós-Graduação em Ciência Florestal, Universidade Federal de Viçosa, Laboratório de Celulose e Papel, Campus UFV, CEP 36570-000, Viçosa (MG), Brasil. lucas_c_barbosa@hotmail.com

2 Engenheira Floresta, Dra ${ }^{\mathrm{a}}$, Professora Adjunta do Departamento de Ciências Florestais, Centro de Ciências Rurais, Universidade Federal de Santa Maria, Av. Roraima, 1000, CEP 97105-900, Santa Maria (RS), Brasil. cpedrazzi@terra.com.br.

3 Engenheira Florestal, Dr ${ }^{\mathrm{a}}$, Professora do Centro de Engenharias da Universidade Federal de Pelotas, Rua Conde de Porto Alegre, 793, CEP 96010-290, Pelotas (RS), Brasil. erikaferreira@ufpel.edu.br

4 Engenheiro Industrial Madeireiro, Mestrando pelo Programa de Pós-Graduação em Ciência Florestal, Universidade Federal de Viçosa, Laboratório de Celulose e Papel, Campus UFV, CEP 36570-000, Viçosa (MG), Brasil. guinter_s@hotmail.com

5 Engenheira Florestal, Msc, Doutoranda do Programa de Pós-Graduação em Engenharia de Materiais pela Universidade Federal do Rio Grande do Sul, Av. Paulo Gamia, 110, CEP 90040-060, Porto Alegre (RS), Brasil. vaniakarine@hotmail.com

Recebido para publicação em 9/10/2012 e aceito em 14/12/2012 
medium-sized sawmill in the city ofRio Grande, inRio Grande doSulstate, and to promote physical and chemical analysis of waste wood generated in the sawing process. It was used $20 \operatorname{logs}$ of Pinus elliottii, divided into two diameter classes. The residues, except the sawdust, collected for analysis were disposed in the courtyard of the company in the form of chips.

The following physical and chemical properties of the chips were examined: density, extractives content soluble in acetone, acetyl groups, soluble and insoluble lignin on acid (Klason lignin), uronic groups and carbohydrates. Comparing the results of the wood properties to the ones found in literature, it was evaluated the quantity and quality of waste that can be used as feedstock for the production of kraft pulp. As the main results there was a slight increase of sawing yields in the larger diameters logs compared to the smaller diameters. From the physical and chemical analyses, it was obtained the following results: density of $0.402 \mathrm{~g}$ $/ \mathrm{cm}^{3}$, cellulose content of $43.67 \%$ and $24.37 \%$ for hemicellulose, klason lignin of $26.75 \%$ and $3,80 \%$ for extractives content. As conclusion, the low sawing yield can be associated to the lack of a classification diametric and appropriate diagrams sections, resulting in a greater loss in the form of waste. Regarding the chemical and physical composition of the sawmill residues, the results were within the standards of quality wood used for kraft pulp of softwood material, presenting some advantages over younger woods commonly used in industry.

Keywords: Pinus elliottii; sawmill residues; kraft cellulose.

\section{INTRODUÇÃO}

De modo geral, as indústrias de base florestal apresentam baixo rendimento e geram grande quantidade de resíduos no processo produtivo, principalmente as indústrias de transformação primária como, por exemplo, as serrarias. $\mathrm{O}$ aumento progressivo da demanda por madeira desdobrada tem revelado problemas como o crescimento do consumo da matéria-prima madeira, em um momento em que o mercado apresenta diminuição de oferta deste insumo. Além disso, a geração de quantidades cada vez maiores de resíduos, que muitas vezes não encontram utilizações dentro das próprias indústrias onde são gerados, pode resultar em prejuízos para as mesmas.

O país apresenta um elevado número de serrarias, sendo que a maioria delas ainda é dotada de equipamentos antigos e sem manutenção, que ocasionam baixa produtividade e maior perda de matéria-prima. O emprego mais comum dos resíduos do desdobro, no Brasil, tem sido na queima direta para a geração de energia e, a partir de um período mais recente, no processo de fabricação de painéis aglomerados e MDF (chapas de fibras de média densidade). Entretanto, não se utiliza integralmente esses resíduos devido aos grandes volumes gerados, sua localização descentralizada, ou ainda às grandes distâncias dos centros consumidores, demandando altos custos de transporte. Por falta de uma destinação imediata, grandes quantidades desses resíduos são simplesmente empilhadas, permanecendo nessas pilhas por muitos anos e, atualmente, encontram- se em diversos estágios de decomposição. Muitas vezes, os resíduos são simplesmente queimados a céu aberto, ou sofrem combustão espontânea, com emanação de particulados finos para a atmosfera, provocando problemas respiratórios e reações adversas na população (RECH, 2002).

A utilização de resíduos e sobras deverá ser feita a partir de programas e mecanismos que permitam a agregação de valor aos mesmos. Esta agregação de valor é capaz de aumentar a competitividade das empresas processadoras de madeira, elevando os índices de competitividade do setor como um todo, além de contribuir para a manutenção e criação de empregos diretos e indiretos. O aproveitamento de resíduos pode, ainda, auxiliar as empresas do segmento florestal a se adequarem dentro de parâmetros mais sustentáveis, considerando o risco de impactos ambientais negativos que representa a indevida destinação final de resíduos, especialmente da serragem no caso da madeira.

No Brasil, timidamente, estão se desenvolvendo iniciativas de aliar a produção de celulose a indústrias de outros setores. As primeiras atividades colocadas em prática neste sentido utilizaram a madeira de Pinus sp, com uma melhor aceitação no mercado de madeira serrada, e de grande utilização na indústria de celulose de fibras longas (SANTOS, 1994).

Portanto, o estudo das características de resíduos madeireiros é de grande importância para que se possa comprovar sua viabilidade de utilização 
em outros setores industriais, visando-se a um melhor aproveitamento, sem a perda de qualidade do produto produzido a partir destes resíduos. Desta forma, o presente trabalho teve como objetivos avaliar o rendimento de uma serraria de médio porte, localizada no município de Rio Grande, RS, e promover análises físico-químicas dos resíduos gerados na etapa de desdobro.

\section{MATERIAL E MÉTODOS}

\section{Material}

Os resíduos madeireiros avaliados neste estudo foram fornecidos pela serraria Sena Madeiras, localizada no município de Rio Grande, no Estado do Rio Grande do Sul. A espécie utilizada foi o Pinus elliottii. Foram selecionadas no pátio de madeiras da empresa 20 toras dessa espécie, sendo 10 toras finas referidas como classe 1 e 10 toras grossas referidas como classe 2 (Tabela 1). O comprimento das toras variou de 1,95 a 2,05 m. O sistema de desdobro convencional utilizado pela serraria consiste na entrada das toras aleatoriamente, ou seja, sem nenhuma classificação diamétrica, sendo que, na entrada da serra principal, elas eram classificadas visualmente pelo operador da máquina. Através dessa classificação visual, o operador optava pelo melhor posicionamento da tora sobre o carro porta-tora, definindo o diagrama de corte a ser desenvolvido para cada uma.

TABELA 1: Seleção das toras de Pinus elliottii em duas classes diamétricas.

TABLE 1: Selection of Pinus elliottii logs in two diameter classes.

\begin{tabular}{cccc}
\hline Classe & $\begin{array}{c}\mathrm{N}^{\mathrm{d}} \mathrm{de} \\
\text { Toras }\end{array}$ & $\begin{array}{c}\text { Diâmetro da } \\
\text { tora }(\mathrm{cm})\end{array}$ & $\begin{array}{c}\text { Comprimento da } \\
\text { tora }(\mathrm{cm})^{1}\end{array}$ \\
\hline 1 & 10 & 17 a 21 & $195<\mathrm{C}<205$ \\
2 & 10 & 29 a 43 & $195<\mathrm{C}<205$ \\
\hline
\end{tabular}

${ }^{1}$ Comprimento da tora variável de acordo com a amostra.

Após o procedimento normal de recebimento, as toras foram mensuradas individualmente para a obtenção do volume real. $\mathrm{O}$ volume da casca foi desconsiderado. Utilizando-se um paquímetro digital, foi medida a espessura da casca em 4 pontos das toras, em seguida, obteve-se a média destas medições, valor que foi subtraído do diâmetro com casca, obtendo-se, então, o volume sem casca. Os resíduos coletados para o estudo estavam dispostos no pátio de madeira da empresa. Este material, na forma de cavacos, era derivado de costaneiras, refilos, destopos e tábuas com defeitos, oriundos do processamento mecânico de toras de Pinus elliottii.

\section{Quantificação dos resíduos}

A quantificação dos resíduos gerados pela serraria foi realizada a partir da diferença entre o volume bruto das toras amostradas e o respectivo volume de madeira serrada. Primeiramente, foi mensurado o comprimento das toras com o auxílio de uma trena de cinco metros, enquanto o diâmetro sem casca das duas extremidades foi medido com o auxílio de uma fita métrica. Para a determinação do volume sem casca das toras foi utilizada a equação de Smalian (equação 1).

$$
\mathrm{VSC}=[(\mathrm{g} 1+\mathrm{g} 2) / 2] \times 1 \quad \text { (equação } 1)
$$

Em que:

$\mathrm{VSC}=$ volume sem casca da tora, $\mathrm{em}^{3}$;

$\mathrm{g} 1$ = área basal do diâmetro 1 da tora, $\mathrm{em} \mathrm{m}^{2}$;

g2: = área basal do diâmetro 2 da tora, $\mathrm{em} \mathrm{m}^{2}$;

$1=$ comprimento da tora, em $\mathrm{m}$.

Após a mensuração, as toras foram numeradas e encaminhadas para o processamento mecânico. A madeira serrada de cada tora foi marcada com o respectivo número e empilhada, formando uma pilha para cada tora processada. Posteriormente, foram mensurados o comprimento e a largura, com o auxílio de uma trena. A largura foi mensurada em três pontos: nas extremidades (a dez centímetros dos topos) e na porção mediana. A espessura foi medida nos mesmos pontos que a largura, utilizando-se uma trena. $\mathrm{O}$ volume de cada peça de madeira serrada foi determinado de acordo com a equação 2 .

$$
\mathrm{V}=1 \times \mathrm{b} \times \mathrm{e}
$$

Em que:

$\mathrm{V}=$ volume da peça, em $\mathrm{m}^{3}$;

$1=$ comprimento da peça, em m;

$\mathrm{b}=$ largura média da peça, em $\mathrm{m}$;

$\mathrm{e}=$ espessura média da peça, em $\mathrm{m}$. 
Para definir a quantidade de resíduos na forma de costaneiras, refilo, destopo e serragem foi consultada a literatura. Foram utilizados, mais especificamente, os números da pesquisa de Olandoski et al. (1997), que determinaram uma média de $10 \%$ de serragem, $12 \%$ de costaneiras, $3 \%$ de destopo e $24 \%$ de resíduos de refilo na operação de desdobro de toras de Pinus spp de uma serraria com aproveitamento médio de 51\% em madeira serrada. A partir destas informações e dos volumes de resíduos gerados na serraria em estudo estimou-se a quantidade média de resíduos com potencial de serem destinados à indústria de celulose.

O rendimento de madeira por tora foi expresso pela equação 4 (GOMIDE, 1974; ROCHA, 1999; LATORRACA, 2004):

$$
\mathrm{R}=(\mathrm{VT} / \mathrm{VSC}) \times 100
$$

Em que:

$\mathrm{R}$ : rendimento ou porcentagem de aproveitamento, em \%; VT: volume total de madeira serrada por tora, $\mathrm{em} \mathrm{m}^{3}$; VSC: volume sem casca da tora, $\mathrm{em}^{3}$.

\section{Análises físico-químicas dos residuos}

Após secos ao ar, os cavacos foram armazenados em sacos de polietileno, para uniformização e conservação do teor de umidade. Posteriormente, foram transformados em serragem em moinho Willey, classificados em peneiras 40/60 mesh, secos e armazenados em potes lacrados de vidro. As seguintes propriedades físico-químicas dos cavacos foram analisadas: densidade básica, teor de extrativos em acetona, grupos acetilas, lignina solúvel e insolúvel em ácido, grupos urônicos e carboidratos. Foram adotadas duas repetições para cada análise.

Após as análises, os dados experimentais foram comparados com os resultados de estudos anteriores, com o intuito de verificar a viabilidade da utilização de cavacos provenientes de resíduos da operação de desdobro de uma serraria para a produção de celulose kraft.

As metodologias seguidas para análises químicas das madeiras foram as especificadas na Tabela 2:

A densidade básica dos cavacos foi determinada pela relação entre o peso absolutamente seco e o volume saturado dos cavacos, utilizando-se o método da balança hidrostática, estabelecido na norma ABNT-NBR 11941.

\section{RESULTADOS E DISCUSSÃO}

Quantificação dos resíduos e determinação de rendimento

$\mathrm{Na}$ Tabela 3 são apresentados os resultados para as duas classes diamétricas de Pinus elliottii, com os seus respectivos rendimentos e porcentagens de resíduos originados no processo.

Observa-se na Tabela 3 que o rendimento médio da classe de maior diâmetro foi de $44,07 \%$, enquanto o rendimento médio das toras finas foi de $41,18 \%$, ambos os valores em desacordo com Vital (2008), que considera valores normais de rendimento para coníferas entre 55 e $65 \%$. Notase um leve incremento do rendimento em madeira serrada em função do aumento do diâmetro da tora. Segundo Rocha (2000), é normal, em serrarias, as toras de menores diâmetros apresentarem menores rendimentos. Outro fator que deve ser levado em consideração é a pequena variedade de produtos obtidos das toras, o que pode indicar que toras com diâmetros menores não sejam adequadas para tábuas de determinadas dimensões (MURARA JÚNIOR, 2005).

Cademartori (2010) encontrou rendimentos similares para uma serraria da região sul do Rio Grande do Sul, que também desdobra madeira de Pinus elliottii. O autor avaliou o rendimento de

TABELA 2: Metodologias aplicadas nas análises químicas.

TABLE 2: Chemical composition analysis.

\begin{tabular}{lc}
\hline \multicolumn{1}{c}{ Análise Química } & Metodologia \\
\hline Teor de extrativos solúveis em acetona & ISO 14453 \\
Lignina solúvel em ácido & Goldschimid (1971) \\
Lignina Klason & Gomide e Demuner (1986) \\
Carboidratos (açúcares) & Tappi T249 cm-00, modificada \\
Grupos urônicos & Englyst e Cummings (1984) \\
Grupos acetila & Solar et al. (1987), modificada \\
\hline
\end{tabular}


TABELA 3: Volume sem casca $\left(\mathrm{m}^{3}\right)$, volume de madeira serrada $\left(\mathrm{m}^{3}\right)$, rendimento médio $(\%)$ e porcentagem de resíduos.

TABLE 3: Volume without bark $\left(\mathrm{m}^{3}\right)$, sawed wood volume $\left(\mathrm{m}^{3}\right)$, average yield $(\%)$ and saw percentage.

\begin{tabular}{ccccc}
\hline Classe & Volume da tora sem casca $\left(\mathrm{m}^{3}\right)$ & Volume madeira serrada $\left(\mathrm{m}^{3}\right)$ & $\begin{array}{c}\text { Rendimento médio } \\
\text { da serraria }(\%)\end{array}$ & $\%$ de Resíduos \\
\hline 1 & 0,51 & 0,21 & 41,18 & 58,82 \\
2 & 1,77 & 0,78 & 44,07 & 55,93 \\
Total & 2,28 & 0,99 & 43,42 & 56,58 \\
\hline
\end{tabular}

toras de 15 a $30 \mathrm{~cm}$ de diâmetro, separadas em três classes, e obteve um rendimento médio mínimo de 38,60\% e máximo de 53,77\%. Del Menezzi (1999) relatou que autores como Steele e Wade apontam a tendência de aumento do rendimento em madeira serrada em função do aumento do diâmetro, uma vez que, em toras de maior diâmetro, o volume de madeira perdida como costaneira e no canteamento é porcentualmente menor em relação ao volume da tora.

O volume porcentual médio de resíduos variou entre as toras e entre as duas classes diamétricas. O volume total de resíduos foi de $56,58 \%$, com consequente aproveitamento de $43,42 \%$, o que representa um volume significativo do total de material que não foi transformado em madeira serrada. O porcentual de resíduo observado é similar ao encontrado no desdobro de outras espécies de coníferas por Polzl (2003), entre 55 e $60 \%$, e por Souza (1997), entre 55 e $65 \%$, porém, é superior ao valor obtido por Borges et al. (1993), de 47,7\%.

Em função da grande amplitude diamétrica entre as duas classes, era esperado uma maior diferença em rendimento entre as mesmas. Isto indica que o sistema de desdobro empregado, sem uma classificação diamétrica das toras e sem um diagrama de corte específico, assim como um baixo reaproveitamento das costaneiras, pode ter levado a uma perda considerável de madeira serrada e, consequentemente, afetado o rendimento médio, ocasionando maiores perdas na forma de resíduos.

Na Tabela 4 pode-se observar a distribuição dos resíduos gerados na serraria de acordo com a sua classificação, com base nos valores de Olandoski et al. (1999). Constatou-se que a maior porcentagem de resíduos provém das operações de refilo, seguido pela porcentagem de costaneiras não aproveitadas. Os resíduos, com exceção da serragem, eram recolhidos e transformados em cavacos no picador da empresa. Assim, a quantidade de cavacos gerados
TABELA 4: Distribuição percentual e volumétrica dos resíduos na serraria.

TABLE 4: Percentage and volumetric distribution of the waste of sawmill.

\begin{tabular}{ccc}
\hline Resíduos & Volume $\left(\mathrm{m}^{3}\right)$ & Volume $(\%)$ \\
\hline Costaneira & 0,32 & 13,86 \\
Refilo & 0,63 & 27,71 \\
Destopo & 0,08 & 3,46 \\
Serragem & 0,26 & 11,55 \\
\hline Total & 1,29 & 56,58 \\
\hline
\end{tabular}

a partir dos resíduos representa $45,03 \%$ do total da madeira que entra na serraria e que poderia ser destinada à produção de celulose. Este valor é superior ao relatado por Kock (1976), que afirma que a quantidade de resíduos de uma serraria que pode ser destinado para a obtenção de celulose representa $29 \%$ do total da matéria-prima que entra no processo de desdobro.

A determinação da quantidade de resíduos é importante para o planejamento das atividades de uma serraria. Por exemplo, se a produção média mensal for de $1400 \mathrm{~m}^{3}$ de madeira serrada, como é o caso da empresa avaliada nesse estudo, serão necessários $3224,32 \mathrm{~m}^{3}$ de toras, sem casca, para gerar essa quantidade de madeira serrada. A quantidade de resíduos gerada, por sua vez, será de $1824,32 \mathrm{~m}^{3}$, levando em conta o rendimento médio da serraria. Além disso, $1451,91 \mathrm{~m}^{3},(45,03 \%$ do total do volume de madeira que entra na serraria) desses resíduos podem ser transformados em cavacos que, por sua vez, poderão ser comercializados como matéria-prima para a produção de celulose.

\section{Propriedades físico-químicas da madeira}

Os resultados médios obtidos para a caracterização físico-química da madeira, 
TABELA 5: Características físico-químicas dos resíduos madeireiros.

TABLE 5: Physical and chemical analysis of waste wood.

\begin{tabular}{|c|c|c|c|}
\hline Características & & Média & \\
\hline Densidade Básica $\left(\mathrm{g} / \mathrm{cm}^{3}\right)$ & & 0,402 & \\
\hline Celulose (\%) & & 37,42 & \\
\hline \multirow{7}{*}{ Hemiceluloses (\%) } & Xilanas & & 5,22 \\
\hline & Grupo acetila & & 1,20 \\
\hline & Ácido urônico & & 3,05 \\
\hline & Galactanas & & 2,41 \\
\hline & Mananas & & 11,53 \\
\hline & Arabinanas & & 0,96 \\
\hline & Total & & 24,37 \\
\hline Extrativos (\% solúvel em acetona) & \multicolumn{3}{|c|}{3,80} \\
\hline Lignina insolúvel (\%) & \multicolumn{3}{|c|}{26,40} \\
\hline Lignina solúvel (\%) & \multicolumn{3}{|c|}{0,35} \\
\hline Lignina Total (\%) & \multicolumn{3}{|c|}{26,75} \\
\hline
\end{tabular}

provenientes de duas repetições, estão expostos na Tabela 5.

A influência da densidade básica na qualidade da polpa produzida é, frequentemente, objeto de estudos e pesquisas. Buscando correlacionar esta propriedade, isoladamente, com as propriedades da polpa, diversos trabalhos foram consultados e discutidos.

De acordo com a Tabela 5, o valor correspondente à densidade básica $\left(0,402 \mathrm{~g} / \mathrm{cm}^{3}\right)$ foi abaixo do esperado para a espécie de Pinus elliottii. Como grande parte dos resíduos da serraria transformados em cavacos é proveniente de costaneiras e sobras de madeira, esperava-se uma densidade básica mais elevada, pelo fato de se tratar de madeiras mais velhas, em média 23 anos de idade, e de regiões mais afastadas da medula e próximas a casca onde há maior proporção de madeira adulta e de lenho tardio.

Foelkel et al. (1976), estudando as propriedades da celulose kraft de Pinus elliottii de madeiras juvenil e adulta, encontraram uma diferença considerável entre as densidades básicas dessas madeiras. As amostras de madeira adulta apresentaram densidade básica média de $0,545 \mathrm{~g} /$ $\mathrm{cm}^{3}$, enquanto para amostras de madeira juvenil este valor decaiu para $0,412 \mathrm{~g} / \mathrm{cm}^{3}$.

Silva Júnior (1993), avaliando as características tecnológicas de resíduos de serraria e laminação de Pinus caribaea var. hondurensis frente ao processo kraft de produção de celulose, encontrou densidade básica de madeira de costaneiras de 23 anos de idade com média mais alta $\left(0,6238 \mathrm{~g} / \mathrm{cm}^{3}\right)$ quando comparada com madeiras de 8 anos de idade, de miolo e de topo. Por outro lado, estudando a variação da densidade básica de Pinus elliottii var. elliottii encontrou uma média de $0,319 \mathrm{~g} / \mathrm{cm}^{3}$ para árvores de 7 anos de idade e $0,326 \mathrm{~g} / \mathrm{cm}^{3}$ para árvores dessa mesma espécie com 9 anos de idade. Condizendo com esses valores, Foelkel et al. (1971), avaliando os métodos para determinação da densidade básica de coníferas e folhosas, encontraram uma média de $0,316 \mathrm{~g} / \mathrm{cm}^{3}$ para Pinus elliottii com 8 anos de idade. Já Palermo et al. (2003), analisando a densidade básica de madeiras de diversas idades de Pinus elliottii Engelm., provenientes de um campo experimental de Itapetininga, São Paulo, encontraram uma média de $0,467 \mathrm{~g} / \mathrm{cm}^{3}$ para árvores de 8 anos de idade. Os autores recomendaram árvores com essa faixa etária para as indústrias de polpa e papel.

Foelkel et al. (1975) realizaram um estudo sobre as variações das características da madeira e propriedades da celulose sulfato de Pinus oocarpa em função da idade. O valor da densidade encontrado pelos autores para a madeira de 12 anos foi de $0,412 \mathrm{~g} / \mathrm{cm}^{3}$, próximo ao valor encontrado neste estudo. Os autores obtiveram, após o processo de cozimento, valores de $43,4 \%$ e $4,3 \%$, correspondentes ao rendimento depurado e teor de rejeitos, respectivamente. Resultados satisfatórios e dentro da faixa característica para madeiras de 
coníferas, que compreende 40 a $45 \%$ de rendimento depurado. Segundo Bassa (2006), o rendimento em polpa é uma característica de extrema importância em uma unidade industrial, pois exerce influência sobre a geração de sólidos dissolvidos no licor de cozimento, que serão queimados na caldeira de recuperação, sobre o consumo específico de madeira e, consequentemente, sobre os custos de produção. Desse modo, quanto maior o rendimento depurado, menor será a geração de sólidos, bem como o consumo específico de madeira e os custos de produção de polpa celulósica em uma unidade industrial.

Silva Júnior (1993) observou densidade básica de $0,396 \mathrm{~g} / \mathrm{cm}^{3}$, valor próximo ao encontrado neste trabalho, para madeiras de Pinus taeda de 20 anos. $\mathrm{O}$ autor analisou a produção de celulose por cozimento em função da densidade básica e idade da madeira e obteve um ganho de $24 \%$ em celulose com a utilização da madeira de 20 anos, quando comparada com a de 8 anos, de densidade $0,332 \mathrm{~g} / \mathrm{cm}^{3}$.

Dessa forma, a utilização dos resíduos da serraria pode representar um aumento na produção da celulose, levando-se em conta que a densidade básica desses materiais é geralmente maior do que a de madeiras utilizadas pela indústria celulósica, onde se utilizam madeiras mais novas, com alta proporção de lenho juvenil.

Com relação à composição química da madeira, pode-se observar na Tabela 5 que o teor de celulose, hemiceluloses, lignina e de extrativos totais foram de $37,42 \%, 24,37 \%, 26,75 \%$ e $3,80 \%$, respectivamente. Estes valores encontram-se dentro da faixa característica da composição química de madeiras de coníferas e similares aos encontrados por Lima (2009), ao analisar a composição química de cavacos com casca de Pinus spp. oriundos de resíduos de serrarias. Entretanto, o teor de extrativos foi significativamente menor ao encontrado pelo autor, que foi de $5,8 \%$, em razão da quantidade excessiva de casca presente nas amostras. Para a produção de celulose, os extrativos são compostos indesejáveis, pois reduzem o rendimento e a qualidade da polpa. No entanto, na produção de energia alguns contribuem para aumentar o poder calorífico da madeira (PHILIPP e D'ALMEIDA, 1988). O mesmo autor obteve, após o cozimento, um rendimento depurado de $44,8 \%$, comprovando a viabilidade da utilização de material proveniente de resíduos de serraria para produção de celulose.

Os teores de lignina e carboidratos presentes na madeira foram próximos aos encontrados por Silva Júnior (1993), ao avaliar as características tecnológicas de resíduos de serraria e laminação da madeira de Pinus caribaea var. hondurensis frente ao processo kraft de produção de celulose. $\mathrm{O}$ autor observou um maior teor de holocelulose (celulose + hemiceluloses) e menores teores de lignina e extrativos totais dos resíduos, quando comparados com materiais de 8 anos de idade e de miolo (parte central da tora), o que contribuiu para que esses materiais gerassem celuloses com maiores rendimentos $(52 \%)$ e menores números kappa. Concluiu, portanto, que os resíduos de serraria dessa espécie apresentam potencial para serem usados como matéria-prima para a produção de celulose kraft.

O teor de lignina foi menor que o encontrado por Foelkel et al. (1975) para Pinus elliottii, com 8 anos de idade. Isto pode ser explicado pela maior idade das árvores que constituíram a amostra, com média de 23 anos, uma vez que o aumento da idade da árvore resulta no decréscimo no teor de lignina. Segundo Cardoso et al. (2002), quanto maior o teor de lignina, maior a carga de álcali necessária para efetuar a deslignificação e, um aumento na carga de álcali provocaria maior degradação e dissolução dos polissacarídeos, provocando redução no rendimento.

As galactoglicomananas exibiram menos da metade da composição química da madeira, $37,42 \%$ do peso da madeira, enquanto as mananas constituíram a maior fração das hemiceluloses $(11,53 \%)$. Em relação aos demais carboidratos, incluindo as galactanas, xilanas e arabinanas, não representaram uma fração significativa do peso da madeira, tendo as arabinanas constituído apenas $0,96 \%$ da madeira.

$\mathrm{Na}$ constituição química das xilanas foram determinados, além da unidade monomérica básica de xilose, os teores dos grupos laterais conectados à cadeia básica, abrangendo os ácidos urônicos. Os ácidos urônicos, incluindo os glucurônicos e os galacturônicos, representaram uma fração significativa da madeira, cerca de $3 \%$. Segundo Gomide et al. (2005), a importância do grupo das xilanas está relacionada com o consumo de álcali durante a polpação, com consequente hidrólise e dissolução, e com a transformação em ácidos hexenurônicos, indesejáveis nas operações de branqueamento.

$\mathrm{O}$ teor dos grupos laterais de acetila das hemiceluloses foi de $1,2 \%$. A presença de grupos acetila constitui uma desvantagem tecnológica, 
pois, além de consumir álcali durante o cozimento kraft, representa perda de rendimento, uma vez que são totalmente hidrolisados e solubilizados durante o cozimento (GOMIDE, 2000).

Os resultados das análises químicas, incluindo as hemiceluloses de menor peso molecular, estão de acordo com os encontrados por Sievers et al. (2008) e Sjöström (1999). No entanto, o teor de lignina mostrou-se inferior aos encontrados por esses autores para madeira de Pinus, que foi superior a $30 \%$.

Com base nos resultados obtidos nas análises químicas e na literatura consultada podese afirmar que não há indicativos negativos que venham a comprometer o processo de polpação $k r a f t$ e a qualidade da polpa quando se utilizam resíduos madeireiros para esse fim. $\mathrm{O}$ menor teor de lignina verificado nos resíduos da serraria representa um fator positivo ao processo de obtenção da celulose. Segundo Bassa (2002), os processos químicos de polpação são influenciados pela composição química da madeira, que é determinante na eficiência do processo de polpação, influenciando no consumo de reagentes, no rendimento em polpa celulósica, na quantidade de sólidos gerados e outros fatores. Os extrativos e a lignina são constituintes considerados indesejáveis no processo de produção de celuloses químicas, sendo, suas determinações, indicativos que podem propiciar, indiretamente, estimativas sobre rendimento de processo e consumo de reagentes durante a polpação.

\section{CONCLUSÕES}

O baixo rendimento em madeira serrada pode ter sido influenciado pela falta de uma classificação diamétrica das toras e diagramas de cortes apropriados, assim como a baixa eficiência no reaproveitamento das costaneiras, resultando numa perda média de $56,58 \%$.

Os resíduos que podem ser comercializados para a indústria celulósica representam, em média, $45 \%$ da matéria-prima total que entra na serraria. Em relação à produção mensal da empresa, isso representa um volume de $1451,9 \mathrm{~m}^{3}$ de resíduos, que são picados e transformados em cavacos todo mês.

Com base nos resultados das análises químicas e densidade básica da madeira, pode-se afirmar que os resíduos madeireiros da etapa de desdobro, com exceção do material contendo casca, encontram-se dentro dos padrões de qualidade da madeira utilizada como matéria-prima para fabricação de celulose kraft de fibra longa.

Em algumas situações, os resíduos apresentaram vantagens quando comparados com outras madeiras do mesmo gênero, que normalmente suprem a indústria celulósica, geralmente com ciclo de vida mais curto, como maior densidade básica e menor teor de lignina.

Como a indústria de celulose e papel requer uma demanda muito grande de matéria-prima, seria interessante a organização, por parte das serrarias, para destinarem seus resíduos para esse setor. Do mesmo modo, seria interessante para a indústria poder contar com resíduos fibrosos de baixo custo e de boa qualidade.

\section{REFERÊNCIAS BIBLIOGRÁFICAS}

ASSOCIAÇÃO BRASILEIRA DE NORMAS TÉCNICAS DE CELULOSE E PAPEL-ABTCP. Normas. Rio de Janeiro, ABNT, 2003.

BASSA, A. Processo de polpação Kraft convencional e modificado com madeiras de $E$. grandis e Híbrido (E. grandis $x$ E. urophylla). 2002. 103 f. Dissertação (Mestrado em Ciências Florestais) - Escola Superior de Agricultura "Luiz de Queiroz", Universidade de São Paulo, Piracicaba, 2002.

BASSA, A. G. M. C. Misturas de madeiras de Eucalyptus grandis $x$ Eucalyptus urophylla, Eucalyptus globulus e Pinus taeda para produção de celulose Kraft através do processo Lo-Solids ${ }^{\circledR}$. 2006.169 f. Dissertação (Mestrado). Escola Superior de Agricultura Luiz de Queirós, Piracicaba, 2006.

BORGES, A. S. E. T.; GINIGLIO, G.; BRITO, J. O. Considerações energéticas e econômicas sobre resíduos de madeira processada em serraria. In: CONGRESSO FLORESTAL PANAMERICANO, 1.; CONGRESSO FLORESTALBRASILEIRO, 7., 1993, Curitiba. Anais... Curitiba, 1993. v. 3. p. 603-606.

CADEMARTORI, P. H. G. de. Qualidade da madeira serrada de Pinus elliottii Engelm procedente de florestas resinadas da região Sul do Rio Grande do Sul. 2010. 82 f. Trabalho de Conclusão de Curso - Faculdade de Engenharia Industrial Madeireira. Universidade Federal de Pelotas, Pelotas, 2010.

CARDOSO, V. C. et al. Otimização das condições do cozimento Kraft de Eucalyptus globulus em função do teor de lignina na madeira. In: CONGRESSO E EXPOSIÇÃO ANUAL DE CELULOSE E PAPEL, 
ABTCP, 2002, São Paulo. Anais ... São Paulo: ABTCP, 2002. p. 1-19.

DEL MENEZZI, C. H. S. Utilização de um método combinado de desdobro e secagem para a produção de madeira serrada de Eucalyptus grandis Hill ex-Maiden e Eucalyptus cloeziana F. Muell. 1999. 85 f. Dissertação (Mestrado em Ciência e Tecnologia de Madeiras) - Escola Superior de Agricultura ''Luiz de Queiroz", Piracicaba, 1999.

ENGLYST, H. N.; CUMMINGS, J. H. Simplifiedmethod for the measurement of total nonstarch polysaccharide by gas-liquid chromatography of constituent sugara as alditol-acetates. Analyst, v. 109, n. 7, p. 937-942. 1984.

FOELKEL, C. E. B. et al. Variabilidade no sentido radial de madeira de Pinus elliotti. IPEF, Piracicaba, v. 10, p.1-2, 1975.

FOELKEL, C. E. B. Celulose kraft de Pinus spp. O papel, São Paulo, v. 38, n. 1, p. 49- 67, jan.1976. GOLDSCHMID, O. Ultraviolet spectra. In: SARKANEN, K. V.; LUDWIG, C. H. (Eds). Lignins. New York: Wiley-Interscience, 1971. p. 241-266.

GOMIDE, J. L. Serraria. Viçosa: Universidade Federal de Viçosa-Imprensa Universitária, 1974. $119 \mathrm{p}$.

GOMIDE, J. L.; DEMUNER, B.J. Determinação do teor de lignina em material lenhoso: Método Klason modificado. O Papel, v. 47, n. 8 p. 36-38, 1986.

GOMIDE, J. L.; FANTUZZI NETO, H. Aspectos fundamentais da polpação kraft de madeira de Eucalyptus. O Papel, v. 3 n. 61, p. 62-68, 2000.

GOMIDE, J. L. et al. Caracterização tecnológica, para produção de celulose, da nova geração de clones de Eucalyptus do Brasil. Revista Árvore, Viçosa, v. 29, n. 1, p. 129-137, 2005.

KOCK, P. Material balances and energy required for manufacture of ten wood commodities. Energy and the wood products industry. Forest Products Research Society. Georgia, 1976. 173 p.

LATORRACA, J. V. F. Processamento mecânico da madeira. Seropédica: Universidade Federal Rural do Rio de Janeiro, 2004. 116 p.

LIMA, A. S. Aproveitamento de resíduos de serraria para a produção de celulose kraft branqueada. Trabalho de Conclusão de Curso. Engenharia Industrial Madeireira. UNESP. Campus Experimental de Itapeva. 2009. $41 \mathrm{p}$.

MURARA JUNIOR, M. I. Desdobro de toras de Pinus utilizando diagramas de corte para classes diamétricas. 2005. 67 f. Dissertação (Mestrado em Engenharia Florestal) - Universidade Federal do Paraná, Curitiba,2005.

OLANDOSKI, D. P.; BRAND, M. A.; GORNIAK, E. Avaliação do rendimento, quantidade, qualidade e aproveitamento de resíduos no desdobro de Pinus spp. $5^{\circ}$ EVINCI - Evento de Iniciação Científica da UFPR. Curitiba, 1997. p. 379.

PALERMO, G. P. M. et al. Análise da massa específica da madeira de Pinus elliotti Engelm. por meio de radiação gama de acordo com as direções estruturais (longitudinal e radial) e a idade de crescimento. Floresta e Ambiente, Rio de Janeiro, v. 10, n. 2, p. 47-57, 2003.

PHILIPP, P; D’ALMEIDA, M. L. O. Celulose e Papel. Volume I. Tecnologia de Fabricação da Pasta Celulósica. 2. ed. São Paulo: Instituto de Pesquisas Tecnológicas do Estado de São Paulo - Centro Técnico em celulose e papel, 1988.

POLZL, W. B. et al. Cadeia produtiva do processamento mecânico da madeira - segmento da madeira serrada no Estado do Paraná. Floresta, v. 33, n. 2, p. 127-134, 2003.

$\mathrm{RECH}, \mathrm{C}$. Estudo sugere uso de serragem como insumo. Revista da Madeira, Curitiba, n. 66, 2002.

ROCHA, M. P. Desdobro primário da madeira. Curitiba: Fupef, 1999. 61 p. (Série Didática $\mathrm{n}^{\circ} 02 / 99$ )

ROCHA, M. P. Eucalyptus grandis Hill ex Maiden e Eucalyptus dunnii Maiden como fontes de matéria prima para serrarias. 2000. 185 f. Tese (Doutorado em Engenharia Florestal) - Setor de Ciências Agrárias, Universidade Federal do Paraná, Curitiba, 2000.

SANTOS, J. A. Tecnologia de transformação do eucalipto para madeira maciça. In: III CONGRESSO FLORESTAL NACIONAL, 3., 1994, Figueira da Foz, Portugal, 1994. Anais... Figueira da Foz, 1994. p. 232- 243.

SIEVERS, C. et al. Quantitative solid state NMR analysis of residues from acid hydrolysis of loblolly pine Wood. Atlanta: Ind. Eng. Chem. Res., 2008.

SILVA JÚNIOR, F. G. Utilização múltipla da madeira de Pinus caribaea var. hondurensis para produção de celulose kraft. In: ANAIS DO WORKSHOP "QUALIDADE DA MADEIRA EM PINUS”, Piracicaba, 1992. Série Técnica do IPEF, Piracicaba, v. 9, n. 27, p. 56-62. 1993.

SJÖSTROM, E. Wood chemistry: fundamentals and applications. New York: Academic 
Press, 1993. 293 p.

SJÖSTRÖM, E. Wood Chemistry, 2nd ed., New York: Academic Press, New York, 1999.

SOLAR, R.; KACIK, F.; MELCER, I. Simple semimicro method for the determination of oacetyl group in wood and related materials. Nordic Pulp \& Paper Research Journal. v. 4, p. 139-141, 1987. SOUZA, M. R. Tecnologias para usos alternativos de resíduos florestais. Experiências do laboratório de produtos florestais - IBAMA, na área de utilização de resíduos florestais e agrícolas. In: WORKSHOP SULAMERICANO SOBRE OS USOS ALTERNATIVOS DE RESÍDUOS DE ORIGEM FLORESTAL E URBANA, 1997, Curitiba. Anais... Curitiba, 1997. p. 49-70. TECHNICAL ASSOCIATION OF THE PULP AND PAPER INDUSTRY-TAPPI. Tappi test methods: 1992-1993. Atlanta: 1992.

VITAL, B. R. Planejamento e Operações de Serrarias. Viçosa: UFV, 2008. 211 p. 